\title{
Carbon Dioxide Flux Measurement Systems Handbook
}

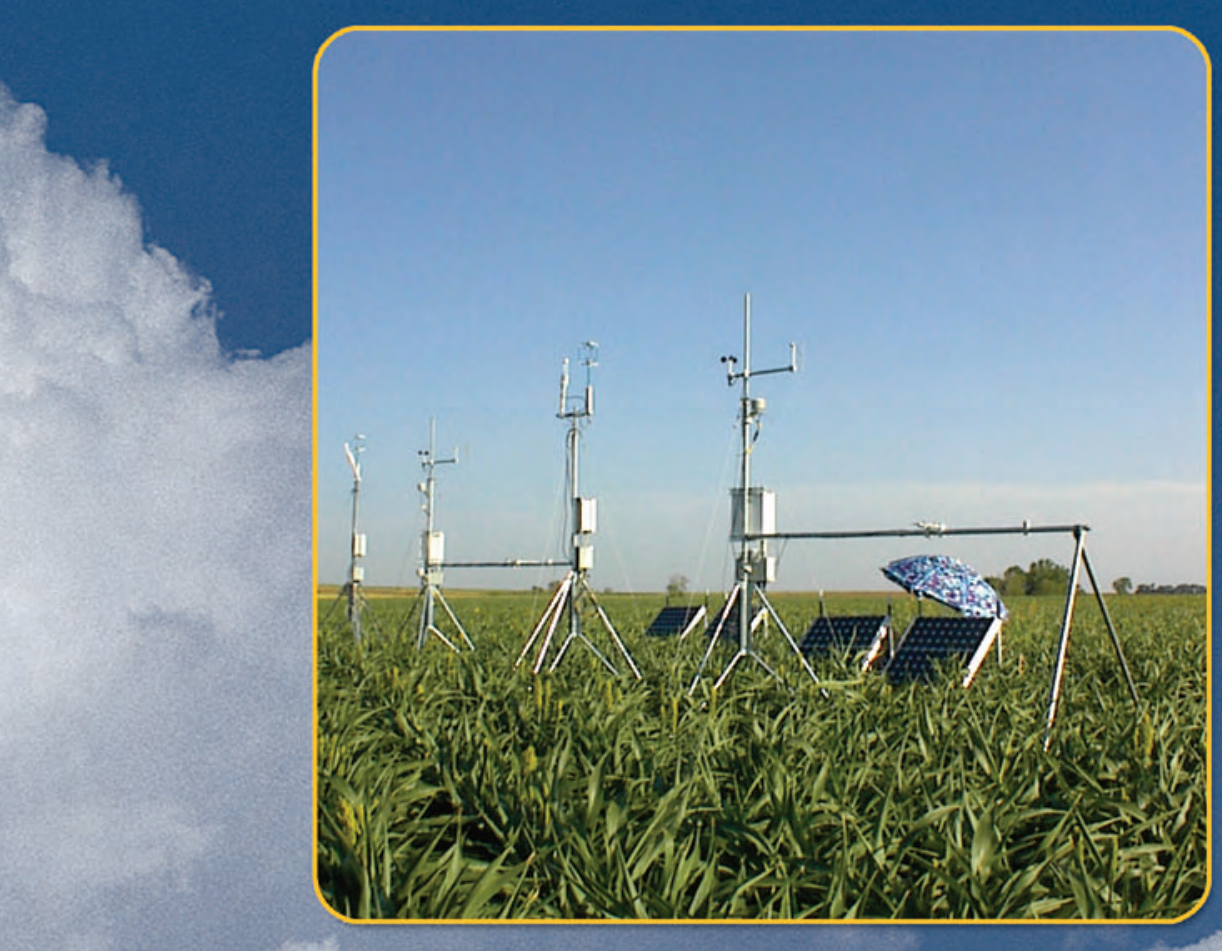

January 2005

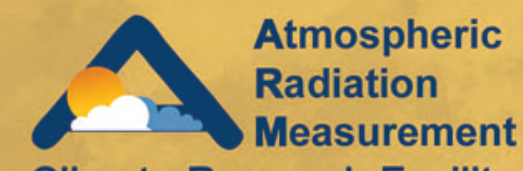

Climate Research Facility

U.S. Department of Energy 


\section{Carbon Dioxide Flux Measurement Systems $\left(\mathrm{CO}_{2} \mathrm{FLX}\right)$ Handbook}

January 2004

M.L. Fischer

Work supported by the U.S. Department of Energy, Office of Science, Office of Biological and Environmental Research 


\section{Contents}

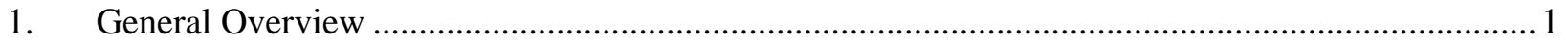

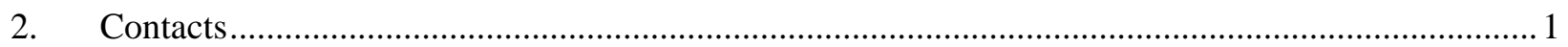

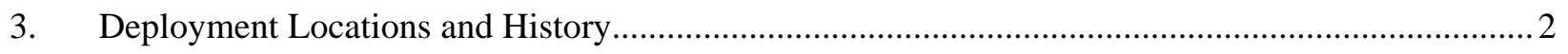

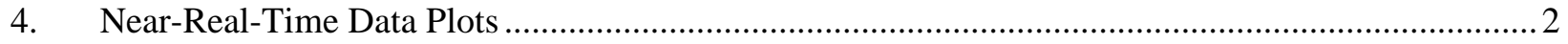

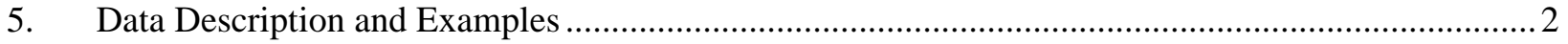

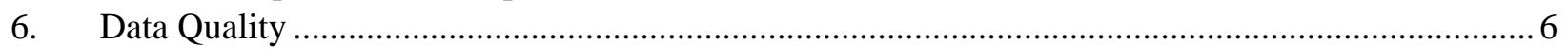

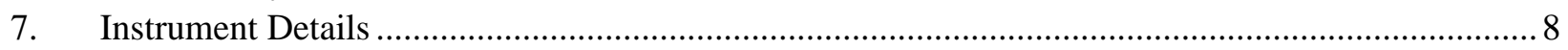

Tables

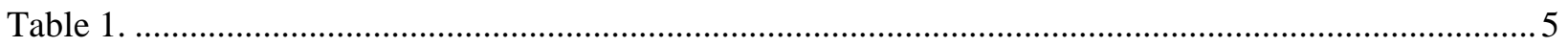

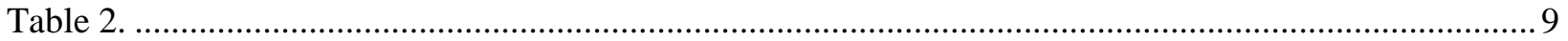




\section{General Overview}

The Southern Great Plains (SGP) carbon dioxide flux ( $\mathrm{CO}_{2}$ flux $)$ measurement systems provide half-hour average fluxes of $\mathrm{CO}_{2}, \mathrm{H}_{2} \mathrm{O}$ (latent heat), and sensible heat. The fluxes are obtained by the eddy covariance technique, which computes the flux as the mean product of the vertical wind component with $\mathrm{CO}_{2}$ and $\mathrm{H}_{2} \mathrm{O}$ densities, or estimated virtual temperature. A three-dimensional sonic anemometer is used to obtain the orthogonal wind components and the virtual (sonic) temperature. An infrared gas analyzer is used to obtain the $\mathrm{CO}_{2}$ and $\mathrm{H}_{2} \mathrm{O}$ densities. A separate sub-system also collects half-hour average measures of meteorological and soil variables from separate 4-m towers.

\section{Contacts}

\subsection{Mentor}

Marc L. Fischer, Staff Scientist

Atmospheric Sciences Department

Environmental Energy Technologies Division

Mail Stop 51-208

E.O. Lawrence Berkeley National Laboratory

1 Cyclotron Rd.

Berkeley, CA 94720

Phone: (510) 486-5539

Fax: (510) 486-5298

email: mlfischer@lbl.gov

web page: http://eetd.lbl.gov/env/mlf/

\subsection{Instrument Developer}

David P. Billesbach, Research Professor

206 L.W. Chase Hall

University of Nebraska

Lincoln, NE 68583

Phone: (402) 472-7961

email: dbillesbach1@unl.edu

For instrument repair and maintenance:

Gill Solent, UK

US Dist. Texas Electronics

Phone: (800) 424-5651

Website: http://www.gill.co.uk/

Licor Environmental

Lincoln, Nebraska

Phone: (800) 447-3576

Website: http://env.licor.com/ 
Campbell Scientific

Logan, Utah

Phone: (435) 753-2342

Website: http://www.campbellsci.com/

\section{Deployment Locations and History}

The number and location of the sensors on the SGP 60-m tower has changed over time; the following changes have been made:

September 2000. Initial installation of one system on the southeast boom at $60 \mathrm{~m}$ on the Central Facility (CF) tower.

December 2002. First system removed from southeast boom. Systems installed on the 25- and 60-m west booms on the CF tower. Combined eddy covariance system at 4.5-m and supporting 4-m meteorological measurement tower installed near base of 60 -m tower.

\section{Near-Real-Time Data Plots}

See data quicklooks from yesterday at:

- yest60m

- yest $25 \mathrm{~m}$

- yest $4 \mathrm{~m}$

\section{Data Description and Examples}

\subsection{Data File Contents}

The data are presented in three levels of processing: a1, b1, and b1met. Each level of processing has an accordingly named directory. For more detailed information on processing, please see Data Processing Algorithms section. In summary:

Directory 'a1': sgp30p1flxT1.a1.YYYYMMDD.000000.cdf

First level of processing where raw data are converted to physical units, despiked, lag is corrected, statistics are calculated, etc. "YYYYMMDD" denotes year, month, day of the file. All data are in cdf format.

Directory 'b1': sgp30p1flxT1.b1.YYYYMMDD.000000.cdf

Second level of processing where data are quality checked and corrections applied properly rotated.

Directory 'b1met': sgp30p1flxmetT1.b1.YYYYMMDD.000000.cdf

Third level of processing where other meteorological data are added to the b1 level of processing 


\subsubsection{Primary Variables and Expected Uncertainty}

The $\mathrm{CO}_{2}$ flux systems measurement systems provide from $1 / 2$ - to 4-hour mean estimates of the fluxes of $\mathrm{CO}_{2}, \mathrm{H}_{2} \mathrm{O}$ (latent heat), and sensible heat from a variable area (footprint) of the land surface upwind of the instrument. In rough terms, the extent of the footprint, which depends on the mean wind speed and the degree of turbulent mixing in the atmosphere, varies from 5-100 times the height of the sensors above the land surface. For example, the instrument located at $60 \mathrm{~m}$ on the CF tower detect land surface fluxes at distances between approximately $0.3-6 \mathrm{~km}$ from the tower depending on meteorological conditions.

The fluxes are computed from the following directly measured data. The sonic anemometer at $10 \mathrm{~Hz} \mathrm{CO}_{2}$ meausres orthogonal components of the wind velocity, $\mathrm{u}, \mathrm{v}$, and $\mathrm{w}\left(\mathrm{m} \mathrm{s}^{-1}\right)$, and sonic temperature $(\mathrm{K})$, which is approximately equal to virtual temperature. An infrared gas analyzer (IRGA) measures $\mathrm{H}_{2} \mathrm{O}$ densities $\left(\mathrm{mmol} \mathrm{m}^{-3}\right)$.

\subsubsection{Definition of Uncertainty}

Uncertainties in the measurements obtained under well-mixed conditions are typically dominated by random noise from atmospheric turbulence and the instrument. The most common source of uncertainy at night is caused by imperfect mixing under low turbulence conditions. A third source of uncertainty is noise caused by airborne material (e.g., rain) that briefly obscures the sound or light path of the sensors. The data processing software is designed to provide diagnostic variables to identify the sources of uncertainty that affect the measurements. See the description of processing algorithms given below.

Under normal operation, the instrument noise limits to flux measurements are as follows:

$\mathrm{CO}_{2}$ flux: detection limit $\sim 0.1 \mathrm{umol} / \mathrm{m}^{\wedge} 2 / \mathrm{s}$, gain uncertainty $1-3 \%$

$\mathrm{H}_{2} \mathrm{O}$ flux: detection limit $\sim 10 \mathrm{~W} / \mathrm{m}^{\wedge} 2 / \mathrm{s}$, gain uncertainty $1-3 \%$

Sensible heat: detection limit $\sim 10 \mathrm{~W} / \mathrm{m}^{\wedge} 2 / \mathrm{s}$, gain uncertainty $1-3 \%$

\subsubsection{Secondary/Underlying Variables}

Secondary variables are provided for assessing the state of the atmosphere including: friction velocity and Monin-Obukhov scale length; radiatiative balance and surface reflectivity variables including upward and downward shortwave, longwave, and photosynthetically active radiation; and soil variables including soil temperature and moisture.

\subsubsection{Diagnostic Variables}

Additional diagnostic variables include the first four statistical moments and spike counts (see below) of wind velocity, $\mathrm{CO}_{2}$ and $\mathrm{H}_{2} \mathrm{O}$ vapor densities, and virtual temperature. 


\subsubsection{Data Quality Flags}

Output files include QC flags as described below:

\section{Raw data Quality Assurance (QA)/QC}

Spike count for u,v,w,T, q, c

This is a summary of the QC flags in a1 and b1 files.

******Flags present in _a1_files:

nspk_unrot_u number of samples out of range u

speed $>40 \mathrm{~m} / \mathrm{s}$

deviation from mean $>6 *($ std dev $)$

nspk_unrot_v number of samples out of range v

speed $>40 \mathrm{~m} / \mathrm{s}$

deviation from mean $>6 *$ (std dev)

nspk_unrot_w number of samples out of range w

speed $>40 \mathrm{~m} / \mathrm{s}$

deviation from mean $>6 *$ (std dev)

nspk_t number of samples out of range $t$

deviation from mean $>5 *($ std dev $)$

nspk_q number of samples out of range q

value $>2000 \mathrm{mmol} / \mathrm{m}^{-3}$

value $<0 \mathrm{mmol} / \mathrm{m}^{-3}$

deviation from mean $>6 *$ (std dev)

nspk_c number of samples out of range c

$$
\begin{aligned}
& \text { value }>30 \mathrm{mmol} / \mathrm{m}^{-3} \\
& \text { value }<10 \mathrm{mmol} / \mathrm{m}^{-3} \\
& \text { deviation from mean }>6 *(\text { std dev })
\end{aligned}
$$

Processed Data Checks

$* * * * * *$ Flag Scheme in b1 level files: 
Almost every variable ' $\mathrm{x}$ ' has a quality control flag named 'qc_x'. In general, the values of QC flags are as follows:

\section{Table 1.}

qc value

0

1

2

4

8

16

32

\section{relevant condition}

value not suspect

value missing

value below minimun or above maximum or value is +-infinity one or more dependencies failed; see the "dependency" attribute of variable; if a dependency is a spike count, it fails if it is $>100$, if a dependency is a variable, it fails when the variable's qc flag is not equal to 0 .

value has large variance; see "large variance condition" attribute of variable value suspect because variable has more than 100 spikes; these spikes are counted in a1 level data; see "dependencies" attribute of variable; currently this flag applies to t, q, c. value suspect because of another condition, see "special condition" attribute of variable. Currently only applies to fc_corr, wc_2d, ustar.

For more specific minimum, maximum, and other values, please see the Data Description File.

\subsubsection{Dimension Variables}

Each variable has dimensions included in the data files.

\subsection{Annotated Examples}

The variable for $\mathrm{CO}_{2}$ flux is fc_corr $\left(\mu \mathrm{mol} \mathrm{CO}_{2} \mathrm{~m}^{-2} \mathrm{~s}^{-1}\right)$. Typical daytime values are $-30<\mathrm{fc}$ _corr $<10$ $\left(\mu \mathrm{mol} \mathrm{CO} \mathrm{Cm}^{-2} \mathrm{~s}^{-1}\right.$ ). The corresponding quality control variable is qc_fc_corr (dimensionless) which normall has a value of zero. Low turbulence at night is identified as occurring when the mean wind speed is less than $2 \mathrm{~m} \mathrm{~s}^{-1}$.

\subsection{User Notes and Known Problems}

The instruments have provided high quality data for a large fraction ( $>80 \%)$ of their operating lifetime. Occassional loss of data has occurred due to loss of power communications or instrument malfunction. Also, the operation of some of the auxiallary sensors (particularly the soil measurement instruments) has been optimized over time. All data users are strongly urged to review the quality reports describing 
intermittent problems and changes to sensors and the data processing, then refer further questions to the instrument mentor.

\subsection{Frequently Asked Questions}

Where do I get more information?

Contact the instrument mentor at mlfischer@lbl.gov.

\section{Data Quality}

\subsection{Data Quality Health and Status}

Data quality is evaluated by inspecting Quality Control (QC) flags and variables in processed data.

\section{Data Processing Algorithms}

The first program processes the raw (a0) data to produce intermediate (a1) data files. The averaging time for calculations can be varied to produce equipment center (EC) average values for each $1 / 2$ hour (other averaging times can be requested of 1,2 , and $4 \mathrm{hr}$ ). The calculation is performed as follows:

From a0 to a1:

1. Read in raw data and convert to physical units (u,v,w [m/s], $\mathrm{T}$ sonic $[\mathrm{C}], \mathrm{CO}_{2}$ and $\mathrm{H}_{2} \mathrm{O}$ $\left.\left[\mathrm{mmol} / \mathrm{m}^{-3}\right]\right)$.

2. Shift the $\mathrm{CO}_{2}$ and $\mathrm{H}_{2} 0$ signals back by (2 - 3 samples) to correct for a fixed time lag in the LI-7500 analyzer.

Identify and remove spikes from data using 100-second running mean filter. Spikes are identified as data points with values more than a set number of standard deviations away from running mean. Spike data are given value of running mean and are not used to update mean. Spikes are counted and the mean value of the spikes is calculated.

3. Calculate statistics (mean, variance, skewness, and kurtosis) of each variable and covariances between all signal pairs.

4. Calculate 2-D coordinate rotation to zero mean $\mathrm{w}$ and $\mathrm{v}$ and apply to vector and covariance quantities.

5. Write out results.

From a1 to b1: processes intermediate (a1) files to produce estimates of turbulent fluxes with initial QC flags as follows:

1. Compute turbulent fluxes of $\mathrm{CO}_{2}$ and $\mathrm{H}_{2} \mathrm{O}$ including appropriate Webb-Pearmann-Leuning corrections (Webb et al, 1980) for sensible and latent heat (Webb et al, 1980). 
2. Inspect and flag data falling outside of acceptable limits based on variance, spike counts, and turbulence conditions $\mathrm{u}^{*}$.

3. Write out results.

From b1 to metb1:

1. For the 4-m systems, merge meteorological data with b1 data file.

\section{Eddy Covariance Calculations}

The algorithm that computes the turbulent fluxes (a1tob1) for the data collected at $4 \mathrm{~m}$ uses the air temperature, pressure, and relative humidity from meteorological sensors to calculate the density and specific heat. However, at present, the 25 and $60 \mathrm{~m}$ systems use the virtual temperature measured by the anemometer and the $\mathrm{H}_{2} \mathrm{O}$ density measured by the IRGA to estimate air density and specific heat, assuming a constant pressure of $98 \mathrm{kPa}$. This will cause a small errors in cases where pressure or temperature are slightly different from the measured values.

No corrections are made for loss of spectral energy due to sensor separation. Using the work of Moore (1986), we have estimated these corrections to be in the range of 3-7\% for most conditions at $4 \mathrm{~m}$ above the crops, but it is unlikely to be significant for the measurements at 25 and $60 \mathrm{~m}$.

The fluxes only reflect turbulent fluxes and do not include corrections for storage of $\mathrm{CO}_{2}, \mathrm{H}_{2} \mathrm{O}$, or heat in the air between the sensor and the land surface. Although this is unlikely to be an important correction for the 4-m system, this correction is often significant for the 60-m system. We are working to incorporate data from a precision gas system to include a storage correction for the 25- and 60-m heights.

\section{Soil Temperature and Moisture}

Soil temperature sensors were installed at the following depths:

$\mathrm{T} 1, \mathrm{~T} 4=25 \mathrm{~cm} ; \mathrm{T} 2, \mathrm{~T} 5=15 \mathrm{~cm} ; \mathrm{T} 3, \mathrm{~T} 6=5 \mathrm{~cm}$

Soil moisture sensors were installed at the following times:

July 2001: M1, M3, M5, M7 = 15 cm; M2, M4, M6, M8 = 5 cm

December 2002- present: M1, M3, M5, M7 = 25 cm; M2, M4, M6, M8 = 5 cm

A large temperature sensitivity was observed in the soil moisture sensors exhibit. This is evident in sensors located in shallow soil with large temperature variations. This has not been corrected by processing algorithm to date. This correction will be included in future files. People interested in performing their own corrections may want to consider using the diurnal soil temperature variations to diurnal variations in moisture signals. 


\subsection{Data Reviews by Instrument Mentor}

Visual QC frequency: daily to weekly

QC delay: typically 1-2 days

QC type: -

Instrument mentor Marc Fischer and data processing assistant Igor Pesenson routinely view graphical displays produced at Lawrence Berkeley National Laboratory (LBNL). The displays include graphs of $\mathrm{CO}_{2}, \mathrm{H}_{2} \mathrm{O}$, sensible fluxes, mean and variance of $\mathrm{CO}_{2}$ concentration (not corrected for barometric pressure) and wind speed.

\subsection{Data Assessments by Site Scientist/Data Quality (DQ) Office}

All DQ Office and most Site Scientist techniques for checking have been incorporated within DQ HandS and can be viewed there.

\subsection{Value-Added Procedures and Quality Measurement Experiments}

None at present. A gap-filled data file is being developed.

\section{Instrument Details}

\subsection{Detailed Description}

\subsubsection{List of Components}

Components for Eddy Covariance Calculations:

- 3-D Sonic Anemometer, Gill Solent Windmaster Pro

Orthogonal wind velocities $\mathrm{u}, \mathrm{v}$, and $\mathrm{w}$

Range: $\pm 20 \mathrm{~m} / \mathrm{s}$

Accuracy: $u, v=1.5 \%$ root mean square (RMS) error, $\mathrm{w}=3 \%$ RMS error

Resolution: $0.01 \mathrm{~m} / \mathrm{s}$

- $\quad$ Sonic temperature (from speed of sound (SOS))

Range: -40 to +60 deg C (307-367 m s-1)

Accuracy: $3 \%$ RMS error in SOS

Resolution: $0.02 \operatorname{deg} \mathrm{C}$

Infrared Gas Analyzer, Licor Inc. LI-7500 (see http://env.licor.com/)

- $\mathrm{CO}_{2}$ density

Range: 0 to $110 \mathrm{mmol} / \mathrm{m}^{3}$;

Accuracy: $~ 1 \%$ (limited by calibration procedure)

Precision: $\sim 4 \mathrm{umol} / \mathrm{m}^{3}$ (typical RMS instrument noise) 
- H20 density

Range: 0 to $2000 \mathrm{mmol} \mathrm{m}^{-3}$

Accuracy: 1\% (limited by calibration)

Precision: $0.14 \mathrm{mmol} / \mathrm{m}^{3}$ (typical RMS instrument noise)

Data collection system

- 266 - $600 \mathrm{MHz}$ PC clone

- Data collection software:

9/11/2000 - 12/19/2001. Data collection performed with gillsonic.c running under MS

Windows NT (written in C Programming language for MS-DOS at NOAA-ATDD by Tilden Meyers and modified for use at ARM).

12/20/2001 - 12/19/2002. Data collection performed with WinfluxWMP.cpp software running under MS Windows NT (written in C++ by Joe Verfaillie at CSU San Diego).

12/19/2002 - present. Data collection performed with sonic-irga.c software running under Redhat 7.3 (written in C by Ed Dumas at NOAA-ATDD). Note that the data collection system also collects and stores digital serial data from the IRGA.

Table 2.

Components for Meteorological and Soil Measurements Included in 4-m Data Sets:

\begin{tabular}{|c|c|}
\hline Variable measured & Instrument \\
\hline Mean horizontal wind speed and direction & Climatronics CS800-12 wind set \\
\hline Temperature and relative humidity profiles & Vaisala Humiter $50 \mathrm{Y}(2,3 \mathrm{~m})$ \\
\hline Mean atmospheric pressure & Vaisala PTB101B barometer \\
\hline Soil heat flux & $\underline{\text { REBS HFT3 soil heat flux plates (4) }}$ \\
\hline Soil temperature profiles & Type E thermocouples (6) \\
\hline Soil moisture profiles & Decagon ECHO soil moisture sensors (8) \\
\hline Photosynthetically Active Radiation & $\underline{\text { LiCor LI-190SA quantum sensor }}$ \\
\hline $\begin{array}{l}\text { Downwelling Short Wave Radiation (0.4-11 } \\
\text { microns) }\end{array}$ & LiCor LI-200SA pyranometer \\
\hline $\begin{array}{l}\text { Upwelling and downwelling radiation }(0.3 \mathrm{~mm}- \\
2.8 \mathrm{~mm} \text { and } 5 \mathrm{~mm}-50 \mathrm{~mm})\end{array}$ & Kipp \& Zonen CNR-1 radiometer \\
\hline Net radiation & $\underline{\text { Kipp \& Zonen NR-lite net radiometer }}$ \\
\hline Summed precipitation & Texas Instruments TE525 tipping bucket rain gage \\
\hline Data Logger & Campbell CR23x (some systems have CR10x) \\
\hline
\end{tabular}




\subsubsection{System Configuration and Measurement Methods}

Pairs of anemometers and IRGAs are located on and near the CF 60-m tower. Data from the anemometer are transmitted to a personal computer (PC) in an instrument shed at the base of the tower. The PC collects and stores the serial binary data stream from the sonic anemometer and IRGA (for more details, see data collection system notes below). The raw data are transferred to LBNL, processed into the ARM Archive format, and inspected for problems on a daily basis. Processed files are sent to the ARM Archive using the Site Transfer Suite on a weekly basis.

\subsubsection{Specifications}

This section is not applicable to this instrument.

\subsection{Theory of Operation}

Turbulent fluxes are calculated using standard methods in biometeorology. See Section 7.7, Citable References for discussions.

The 3-D sonic anemometer uses three pairs of orthogonal ultrasonic transmit/receive transducers to measure the transit time of sound signals traveling between the transducer pairs. The wind speed along each transducer axis is determined from the difference in transit times. The sonic temperature is computed from the speed of sound, which is determined from the average transit time along the vertical axis. A pair of measurements are made along each axis 100 times per second. Ten measurements are averaged to produce 10 wind measurements along each axis and 10 temperatures each second.

The IRGA measures $\mathrm{CO}_{2}$ and $\mathrm{H}_{2} \mathrm{O}$ densities by detecting the absorption of infrared radiation by water vapor in the light path. Details of the IRGA operation and performance can be obtained from Licor Env. Inc. (http://env.licor.com/PDF_Files/LI7500.pdf).

Data are collected on a standard personal computer. Data are collected in $1 / 2$-hour intervals, using the computer clock start as a time reference. Each $1 / 2$-hour data file has a timestamp reflecting the start time of the file. The computer clock is updated on a regular basis using time server software. The daily collection of 48 raw data files are downloaded from the data collection computer to a processing computer at the LBNL on a daily basis and reduced to produce eddy covariance estimates of turbulent fluxes. A set of data processing algorithms are used to create files suitable for inspection and ingest into the ARM data archive.

\subsection{Calibration}

This section is not applicable to this instrument.

\subsubsection{Theory}

The sonic anemometer does not require maintenance or calibration. The IRGA offset and gain need to be calibrated on a periodic basis. The IRGA is calibrated by introducing gas of know concentration into a calibration hood that surrounds the light path over which infrared absorption is measured. The offset is 
typically calibrated using dry $\mathrm{N}_{2}$ from a gas bottle. The gain of the $\mathrm{CO}_{2}$ and $\mathrm{H}_{2} \mathrm{O}$ channels are calibrated using a bottle with a known concentration of $\mathrm{CO}_{2}$ and flow from a $\mathrm{H}_{2} \mathrm{O}$ vapor generator (e.g. Licor Inc. LI-610 Dew Point Generator).

\subsubsection{Procedures}

This section is not applicable to this instrument.

\subsubsection{History}

The system in longest continuous operation is the system at $60 \mathrm{~m}$ on the $60-\mathrm{m}$ tower. The calibration interval for that system is:

October, 18, 2000

July, 13, 2001

December, 18, 2001

December, 20, 2002; replaced.

The portable flux systems are calibrated before each portable deployment period.

\subsection{Operation and Maintenance}

The sonic anemometer does not require maintenance or calibration. The IRGA offset and gain are calibrated on a periodic basis following the manufacturers recommended procedure.

\subsubsection{User Manual}

This section is not applicable to this instrument.

\subsubsection{Routine and Corrective Maintenance Documentation}

This section is not applicable to this instrument.

\subsubsection{Software Documentation}

General description of the data product formats can be found in the Data Description File.

\subsubsection{Additional Documentation}

This section is not applicable to this instrument.

\subsection{Glossary}

Also see the ARM Glossary. 


\subsection{Acronyms}

CF: Central Facility

DQ: Data Quality

EC: equipment center

IRGA: infrared gas analizer

LBNL: Lawrence Berkeley National Laboratory

PC: personal computer

RMS: root mean square

SGP: Southern Great Plains

SOS: sound of speed

QA: Quality Assurance

QC: Quality Control

Also see the ARM Acronyms and Abbreviations.

\subsection{Citable References}

Kaimal, J.C., Finnigan, J.J., 1994. Atmospheric Boundary Layer Flows: Their Structure and Measurement. Oxford University Press, New York

Moore, C.J., 1986. Frequency Response Corrections for Eddy Correlation Systems. Boundary-Layer Meteorol. 37, 17-35

Paw U, K.T., Baldocchi, D.D., Meyers, T.P., Wilson, K.B., Correction of Eddy-Covariance Measurements Incorporating Both Advective Effects and Density Fluxes. Boundary-Layer Meteorol. $97,487-511$

Webb, E.K., Pearman, G.I., and Leuning, R., 1980. Correction of Flux Measurements for Density Effects due to Heat and Water Vapour Transfer. Quart. J. Roy. Meteorol. Soc. 106, 85-100 